\title{
Diez años de smartphones. Un análisis semiótico-comunicacional del impacto social de la telefonía móvil
}

\author{
Inmaculada Berlanga-Fernández $\left(^{*}\right)$, Vicent Gozalvez-Pérez $\left(^{* *}\right)$, Paula Renés Arellano (**) \\ e Ignacio Aguaded-Gómez (***)
}

${ }^{*}$ ) Universidad Internacional de la Rioja - España $\left(^{* *}\right)$ Universitat de València - España $\left(^{* * *}\right)$ Universidad de Cantabria - España $(* * *)$ Universidad de Huelva - España

\section{RESUMEN}

El teléfono móvil con conexión a Internet (o smartphone) es la tecnología que más rápidamente se ha difundido en la sociedad actual y ha producido hábitos decisivos en los estilos de vida de la ciudadanía. Esta investigación examina desde una perspectiva semióticacomunicacional la relación de diferentes sectores de la sociedad de hoy con estos dispositivos. Se sirve del universo narrativo del programa "Conectados" de la serie Salvados, dedicado precisamente al uso social de esta tecnología justo a los diez años de la aparición del primer smartphone. A través del análisis de los contenidos volcados por los diversos actores que intervienen -adolescentes, adultos, familias, escuela y expertos- se cuestiona si los nuevos dispositivos mediáticos nos empoderan o nos empobrecen y en qué medida lo hacen. La variedad de agentes que intervienen y, especialmente, la entrevista inédita al filósofo Bauman constituyen un amplio prisma social que da solidez a los resultados. Concluye reflexionando cuáles serían las condiciones para un uso autónomo, social, enriquecedor y crítico de tales dispositivos.

Palabras Clave: Teléfonos móviles, comunicación social, semiótica, educomunicación, Programa televisivo Salvados.

\section{Ten years of smartphones. A semiotic-communicational analysis of the social impact of mobile telephony}

\section{ABSTRACT}

Among all new technologies, mobile phones with Internet connection (or smartphones) have most rapidly spread in today's society and produced critical habits in citizens' lifestyles. This paper analyses the narrative universe of "Conectados" from a semioticcommunicational perspective. It is a programme from the series Salvados specifically dedicated to the social use of this technology, exactly ten years since the emergence of the first smartphone. Through the analysis of the content introduced by the various actors involved - adolescents, adults, families, school and experts - at issue is whether the new media devices empower or impoverish us and to what extent. Although the analysis is limited to the contents of a television program, the variety of actors involved and especially the interview unpublished to the philosopher Bauman show a broad social prism and reliable results. It concludes by reflecting on what would be the conditions for an autonomous, social, enriching and critical use of such devices.

Keywords: Smartphones, social communication, semiotics, educommunication, Salvados.

Este trabajo está avalado por la "Red de Educación Mediática" del Programa Estatal de Investigación Científica-Técnica de Excelencia, Subprograma Estatal de Generación de Conocimiento (EDU2016-81772-REDT), financiados por el Fondo Europeo de Desarrollo Regional (FEDER) y Ministerio de Economía y Competitividad de España.

\section{Introducción}

El teléfono móvil con conexión a Internet es la tecnología que más rápidamente se ha difundido en la sociedad actual y que ha producido hábitos decisivos en los estilos de vida de la ciudadanía. Desde que hace 10 años Steve Jobs presentara el primer iphone, la progresiva implantación de los teléfonos inteligentes en nuestras vidas nos ha convertido en personas conectadas 24 horas al día. Además, el aumento de las funciones del móvil y su capacidad para personalizarlas han hecho realidad la afirmación de que "dispositivos como la radio, el navegador, el reproductor de música, la cámara o los buscadores tiendan a desaparecer, una vez integrados en el móvil" (Luengo de la Torre, 2012). De hecho, el informe Horizon-k-12 (Johnson; Adams; Estrada y Freeman, 2014) señalaba al smartphone como una de 
las tendencias a corto plazo (uno o dos años). En este momento la implantación de los dispositivos móviles está consolidada y se puede ver como "modelo revolucionario, simétrico $\mathrm{y}$, en principio, idílico en el que la comunicación llega a todos los estratos sociales otorgando la oportunidad de un feedback (González y Fanjul, 2018).

Los datos de penetración y uso de esta tecnología confirman ya su predominio social. Según el Informe Mobile en España y en el Mundo 2017 (Ditrendia, 2017), a finales de 2016 la penetración de teléfonos móviles en el planeta ascendió al $97 \%$. El número de dispositivos móviles a nivel global ya alcanzó los 7,9 mil millones, más que personas hay en la Tierra. En España los teléfonos móviles inteligentes, representan ya el $88 \%$ del total de teléfonos móviles, lo que sitúa a nuestro país en la primera posición a nivel europeo. Un 37,7\% de los españoles lo considera su equipo principal para acceder a internet y un $92,8 \%$ lo utiliza habitualmente para acceder a la red. En cuanto a la edad de inicio, un $98 \%$ de los jóvenes de 10 a 14 años cuenta con un teléfono de última generación con conexión a Internet. En España, los niños de 2 a 3 años utilizan habitualmente el móvil de sus padres.

Ante estas cifras no es de extrañar que el smartphone, su auge, ventajas, límites y riesgos despierten el interés de las Ciencias Sociales, y se convierta en objeto de estudio de las más diversas disciplinas, conocedoras del papel relevante que juegan las tecnologías emergentes a la hora de educar o formar a la sociedad en ciertos valores, especialmente los valores éticos y cívicos, fundamentales en democracia (Gracia y Gozálvez, 2016). Así, el fuerte impacto que los móviles están ejerciendo en los jóvenes justifica la necesidad de promover actuaciones que contribuyan a un uso más responsable de este tipo de tecnología en todos los ámbitos de su vida personal, escolar y social (Rodríguez-Gómez, Castro y Meneses, 2018).

También los medios de comunicación se hacen eco de este interés general. Es el caso del programa de televisión Salvados que en su emisión del 19 de febrero de 2017 y bajo el título de "Conectados" se interesó por la influencia de esta tecnología en la ciudadanía. Consideramos que el espectro de sectores entrevistados (adolescentes, familias, adultos, psicólogos y sociólogos), el peligro de adicción que se presenta y, en especial, la entrevista inédita al sociólogo y filósofo Zygmunt Bauman (fallecido el mes anterior a la emisión del programa), son circunstancias que hacen que sea de interés el análisis de sus contenidos. También es interesante analizar el formato con el que se presentan estos contenidos al público, como discurso convincente y persuasivo gracias a las estrategias retóricas utilizadas. "Conectados" fue lo más visto del día y congregó a 2,7 millones de espectadores (www.formulatv.com/noticias/64793/audiencias-19-febrero-salvados-espectacular). Lo cierto es que Internet y los medios tienen ciertos riesgos que deben ser abordados desde el campo de la investigación y la formación (Ramos-Soler, López-Sánchez y Torrecillas- Lacave, 2018).

Salvados es un programa de televisión semanal de reportajes de actualidad, producido por Producciones del barrio desde octubre de 2015, y El Terrat desde su inicio en 2008. Se emite los domingos en la cadena La Sexta. Según los expertos el programa ha conseguido combinar el éxito televisivo con el análisis de temas interesantes en un tono distendido (Galán-Linares, 2014, p. 41). Pero a diferencia de lo que suele ser propio de este formato de programas, plantea un periodismo comprometido, que saca a la luz temas de fuerte calado social (Mancinas-Chávez y Galán-Linares, 2014, p. 120).

Así, en los últimos años, Salvados ha sido objeto de diversas publicaciones científicas que se han fijado, bien en sus elevados datos de audiencia (Malaina-Abad, 2015; Cappelletti y Domín- guez, 2014), bien en su repercusión en las redes (Zambrano y Castells, 2016); o lo han estudiado como fenómeno de la televisión social donde la audiencia actúa como prosumidor e interactúa con el periodista que lleva el programa, Jordi Évole, a través de Twitter, Facebook, Youtube o cualquier otra plataforma social, mediante la segunda pantalla_(Merino, 2013, p. 243; 251).

El objetivo principal del presente artículo es investigar si los nuevos dispositivos mediáticos nos empoderan o nos empobrecen; o mejor, en qué sentido ocurre una cosa o la otra, con el fin de perfilar después cuáles serían las condiciones para un uso autónomo, socialmente responsable, enriquecedor y crítico de tales dispositivos (smartphones especialmente).

Para ello se sirve del análisis del programa "Conectados" descrito anteriormente: por su contenido y su formato, bien puede servir como un prisma social cuya visión nos posibilita aproximarnos a este objetivo.

Como objetivos particulares nos proponemos:

1. Conocer la opinión de los diferentes sectores sociales acerca de la eventualidad de estar continuamente conectados a través de los smartphones.

2. Contraponer y sacar a la luz los aspectos positivos y negativos del uso de esta tecnología.

3. Recabar con este análisis un marco de referencia que pueda servir en el diseño de propuestas pedagógicas destinadas a la educación mediática de la ciudadanía (educomunicación).

\section{Metodología}

Como herramienta metodológica aplicaremos un análisis de contenido del universo narrativo del programa que incluya los contenidos volcados, y también la forma elegida para estructurar y desarrollar ese discurso. El análisis se hará desde una perspectiva semiótico-comunicacional. Debemos tener en cuenta que analizar los contenidos de este programa se presenta como una meta-metodología ya que en ellos se incluyen entrevistas a la ciudadanía, un remedo de focus-group a padres, madres y profesorado de escolares, y una entrevista enfocada al filósofo Bauman. Delimitaremos los diversos bloques de contenidos del programa y extraeremos de cada uno las afirmaciones sobre los aspectos positivos y los calificados como negativos en el uso de esta tecnología.

Por su parte, el análisis semiótico favorece profundizar en los códigos de comunicación, su contexto cultural y su composición simbólica, hechos que repercuten en conductas de consumo del medio. Concretamente seguiremos el modelo de Julien Greimas (1917-1992). Este lingüista de origen lituano, perteneciente a la narratología francesa del siglo XX, trató de elaborar una gramática del relato. Para ello efectuó una síntesis de las enseñanzas de Propp, empleando su concepto de actante, y planteó un modelo actancial de gran interés: una estructura simplificada de los roles que los personajes de un relato asumen para el desarrollo de la historia; modelo aplicable a cualquier texto narrativo y que se reduce a seis funciones: un Sujeto desea un Objeto, esto es, un valor: ser amado, dinero, honor, felicidad o poder, entre otros; es ayudado por un Ayudante y orientado por un Oponente; el conjunto de los hechos es deseado, orientado, arbitrado por un Destinador en beneficio de un Destinatario: con frecuencia estos dos últimos roles adquieren una naturaleza social, ideológica o moral. Los roles no son fijos, pueden ser dinámicos. El sujeto es el personaje principal del esquema, y puede ser denominado sujeto y analizado con el modelo cualquier personaje de la historia. Este esquema favorece el interés por la narración. Según los valores y las aspiraciones se perfilan los personajes protagonistas y antagonistas. 
Gráfico 1. Modelo actancial. Fuente: elaboración propia

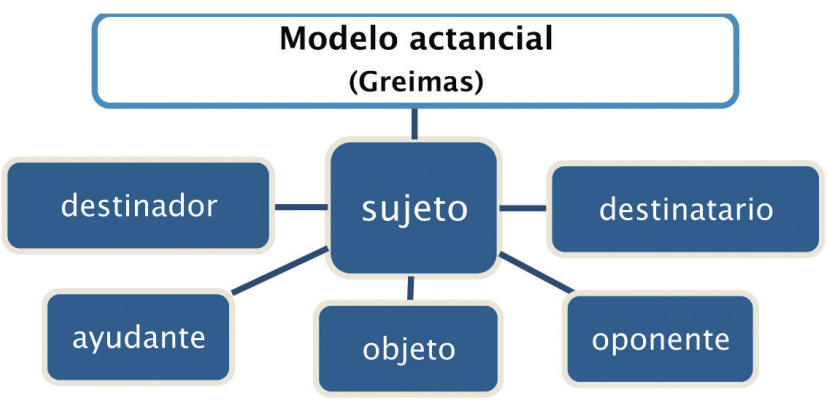

Además, el modelo de Greimas establece hasta tres ejes narrativos fundamentales de todo relato (García-Contto, 2011). En primer lugar, el eje del deseo, donde el sujeto actúa persiguiendo un objeto, y el relato se construye en torno a ese propósito. En segundo lugar, el eje de la comunicación, donde lo que circula es un objeto de conocimiento, ya sea ciencia, información o secretos, y los actantes se definen en función de si donan o reciben esa información o sabiduría. Y finalmente, el eje del poder, también llamado eje de la participación o de los circunstantes, y que sirve para reconstruir las maneras en las que el sujeto recibe autoridad $\mathrm{u}$ objetos que le dan poder para alcanzar el objeto del deseo o evitar un daño.

\section{Gráfico 2. Esquema del eje narrativo de Greimas. Fuente: elaboración propia}

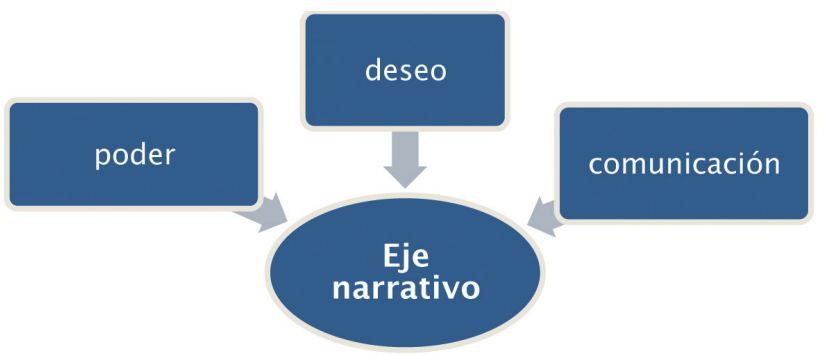

Este triple eje -deseo, comunicación y poder- define de forma precisa la relación de nuestro objeto de estudio: el smartphone. Por tanto los tres posibles ejes narrativos se encuentran perfectamente amalgamados en el desarrollo del programa que hemos analizado.

\section{Resultados}

En este apartado analizamos el programa atendiendo al tema, el formato, la estructura y especialmente, los personajes. En el programa que nos ocupa hay un protagonista: el smartphone, y un hilo conductor, nuestra relación con esta tecnología. En la concreción de esta relación aparecen otros actores, como son los adolescentes, los adultos, las familias y algunos expertos, quienes vuelcan su opinión acerca de estas relaciones y sus consecuencias.

\subsection{El tema: cuestionamiento de las bondades del smartphone}

Un reciente informe de Horizon Report recogía dos interesantes retos "aún de muy difícil definición y solución": lograr un equilibrio entre la vida conectada y la vida desconectada, para no caer en el posible exceso de conexión al que nos aboca el constante bombardeo tecnológico y para no perder de vista su característica de ser una herramienta y no un fin (Horizon Report, 2016).

A estas alturas nadie niega los beneficios de los móviles y de sus múltiples funciones que nos facilitan el quehacer diario. Pero paralelamente al drástico incremento del uso de la tecnología de teléfonos inteligentes crece un sentir social que advierte de los peligros de un uso excesivo. Publicaciones divulgativas alertan de una serie de consecuencias negativas y que coinciden en enumerar una posible adicción, ansiedad y aumento de estrés, la disminución de productividad en el trabajo, la pérdida de intimidad y de espontaneidad en las relaciones, y problemas de socialización o de salud.

Si bien las consecuencias cognitivas y emocionales del uso excesivo de teléfonos inteligentes rara vez han sido examinadas empíricamente (Hartanto y Yang, 2016), comenzamos a ver una serie de publicaciones científicas que fundamentan algunos de estos efectos adversos. Pearson y Hussain (2016) advierten del riesgo de adicción a ciertas aplicaciones web que son fácilmente accesibles a través de teléfonos inteligentes, especialmente redes sociales, y de un aumento en el narcisismo entre sus usuarios. El análisis llevado a cabo por estos investigadores reveló una serie de indicadores que sugieren que los smartphones fomentan el narcisismo, incluso en los usuarios no narcisistas. No obstante, en la discusión de estos resultados los autores animaban a futuras investigaciones que recaben más datos cualitativos en profundidad. Con todo, aconsejan que los compradores de teléfonos inteligentes sean advertidos previamente de las potenciales propiedades adictivas de la nueva tecnología.

Otros estudios sostienen que el uso de los smartphones puede acarrear un deterioro sustancial en las relaciones personales, y encuentran cierta correlación entre el uso de teléfonos inteligentes y la ansiedad social y la soledad (Gao, Li, Zhu, y Liu, 2016), y la ansiedad y la adición (Hartanto y Yang, 2016; Thomée, Härenstam y Hagberg, 2011; Reid y Reid, 2007).

El programa en su totalidad refleja el problema del exceso de conexión a la tecnología, la falta de equilibrio entre la vida conectada y la vida desconectada, y las consecuencias derivadas de este hecho. Todos los actores reconocen que la sociedad está atrapada por los efectos negativos: intuyen soluciones, pero pocas veces se aplican con rotundidad. Se impone el esfuerzo conjunto de todos los actores implicados. Especial atención requiere la educación de los adolescentes, etapa en la que el centro escolar y la familia siguen siendo los principales contextos de socialización, junto con el grupo de iguales, los medios de comunicación y las redes sociales (Rodrigo, Martínez y Rodríguez, 2018).

\subsection{El formato: una historia que refleja la vida real}

La fuerza comunicativa y social de programas como Salvados se basa en las historias que en ellos aparecen, en el modo de articular un discurso narrativo con ritmos y secuencia de contenidos determinados. La narrativa se ha convertido en una especie de llave maestra para la comunicación; las historias suscitan emociones, crean empatía. Con su capacidad de mover la imaginación hacen más activo el acto de comunicación. En consonancia, encontramos que el programa "Conectados" aparece articulado en diversas narraciones: el día a día de una adolescente; la terapia de jóvenes enganchados; conversaciones en una cafetería o la espera de unos padres charlando en la puerta del colegio de sus hijos. Son situaciones cotidianas, cercanas y creíbles, que se desarrollan con personajes concretos, reales y en los escenarios adecuados.

Pero el recurso al storytelling no es algo nuevo. Aristóteles en su Poética nos dejó las bases teóricas de la narrativa actual. Según 
el estagirita todo relato se compone de elementos que deben actuar como un cuerpo único. Es la forma en que la historia conecta de verdad con el público o receptor. Así, Aristóteles divide la narración de cualquier historia en tres actos, los denominados "planteamiento, nudo y desenlace". Y esta estructura tripartita sigue vigente en la actualidad; es más, parece ser que si las historias se cuentan de otra manera no consiguen la tensión dramática que interesa y genera pasión. A juicio de Aristóteles, la narración debe reunir requisitos como la brevedad (incluyendo lo esencial a la causa y omitiendo lo accesorio), credibilidad (necesidad de verosimilitud del relato), el carácter ético (debe reflejar una postura moral), y el carácter patético (la importancia de las pasiones -o pathos- en las acciones narradas debe servir para despertar la emotividad del auditorio).

Vemos que cada una de las narraciones de este programa son concisas y ágiles, características en las que ayuda el empleo de la imagen, la música y las transiciones que otorgan vivacidad al discurso. Los relatos son creíbles: los personajes que actúan son cercanos, por ser conocidos o porque cumplen con la característica de verosimilitud aristotélica: hay una lógica en los argumentos esgrimidos, pueden ser verdaderos y por eso persuaden. Es más, el proceso de los personajes, que se sienten identificados con los testimonios y las tesis de otros actantes del relato, es el mismo proceso que el espectador sufre. Así, es un punto de inflexión el recurso al proceso vivido por el entrevistador, que pasa a ser entrevistado y que se reconoce como adicto a la tecnología.
El testimonio de sus propios compañeros, confirmándolo, y el contenido del epílogo que cerrará la emisión, con la pregunta sobre si Évole está preparado para comenzar la terapia, es un recurso persuasivo decisivo.

El carácter o trasfondo ético-educativo se halla presente a lo largo de todo el programa. Son muchos los valores sociales, familiares y morales (intimidad, autonomía, responsabilidad...) que están en juego. Se habla de adicción y, por tanto, de merma de libertad; de agresividad y chantaje emocional en la familia, de pérdida de interioridad y de soledad. Finalmente, gracias a todos estos requisitos, y a los recursos retóricos empleados de forma sutil pero magistral, la estrategia del pathos está muy lograda: consigue generar emociones y por tanto empatizar con el receptor.

\subsection{La estructura y los protagonistas del programa "Conectados"}

El programa -como ya se ha afirmado- tiene un protagonista, el teléfono móvil, que establece fuertes relaciones con otros actores que vuelcan su opinión acerca de estas relaciones y sus consecuencias.

Aparece estructurado en cuatro bloques según el colectivo vinculado al smartphone: 1) adolescentes 2) adultos 3) familias-escuela 4) expertos. A su vez estos bloques tienen sub-bloques y transiciones organizados según se muestra a continuación (tabla 1).

Tabla 1. Estructura narrativa del programa "Conectados" de Salvados.

\begin{tabular}{|c|c|}
\hline & Estructura narrativa del programa "Conectados" \\
\hline Adolescentes & $\begin{array}{l}\text { (inicio) } \\
\text { - Un día de una adolescente. Créditos iniciales } \\
\text { - Visión de la madre de la adolescente } \\
\text { - Terapia de grupo de adolescentes } \\
\text { - (Transición de imágenes y voz sobre Steve Jobs y el smartphone) } \\
\text { (desarrollo) } \\
\text { · Conversación de Évole con el terapeuta; intervención de los cámaras }\end{array}$ \\
\hline Adultos & $\begin{array}{l}\text { - Testimonio de adultos en videos grabados por ellos mismos } \\
\text { - Entrevista a Gustavo Entrala y a otro adulto } \\
\text { - (Transición de imágenes voz) } \\
\text { - Preguntas a pie de calle }\end{array}$ \\
\hline $\begin{array}{l}\text { Familias/ } \\
\text { profesor }\end{array}$ & $\begin{array}{l}\text { - Diálogo con seis padres de niños de nueve años en la puerta de un centro escolar } \\
\text { - Opinión de un profesor }\end{array}$ \\
\hline Expertos & $\begin{array}{l}\text { - (Transición de imágenes con off de textos de Bauman) } \\
\text { (desenlace) } \\
\cdot \text { Entrevista a Bauman } \\
\text { (epílogo) } \\
\text { Relato sobre la posible terapia de Évole }\end{array}$ \\
\hline
\end{tabular}

En conjunto, el programa sigue la estructura tripartita tradicional de la ficción: tres actos -planteamiento, nudo y desenlace o final- a los que se añade un breve epílogo, cuarto acto o refutador según la teoría de Daniel Tubau (2015)-. El planteamiento lo conformaría la narración protagonizada por los adolescentes. Las imágenes y voz sobre Steve Jobs y el smartphone servirían de transición para el cuerpo, nudo o desarrollo del programa; y el desenlace vendría con la profunda visión del sociólogo Bauman que alerta y hace pensar con su denuncia, en la realidad que da nombre al programa: siempre conectados. El epílogo es una breve nota de humor que engancha con el original momento donde el entrevistador pasa a ser entrevistado y sujeto paciente de la adición a la tecnología.

Bloque-Adolescentes. Este relato comienza mostrando un día cualquiera de Belén, una joven que está siempre pendiente del móvil. Así la vemos en el transporte público mientras escucha música y consulta sus redes, en su centro educativo entre clase y clase e incluso dentro del aula, intentando burlar la vigilancia del profesorado; o con sus amigas hablando de las fotos que ven a través del móvil. Confiesa que nunca ha dejado su teléfono y que si alguna vez se olvidara de cogerlo sería capaz de llegar tarde a sus citas para recuperarlo. Especialmente está pendiente de la red Instagram. En cada sitio se hace una foto y la sube a esta red. Considera que vivir enganchada al móvil es algo normal y que es un hábito que no tiene arreglo. El intento de salirse de la red lo ve una empresa casi imposible pues todos los amigos están dentro. Se da cuenta de lo errado de esta visión, pero no le ve solución.

Interviene también su madre, que describe a su hija como sociable y popular pero que, al vivir siempre pendiente del mó- 
vil, está descentrada. Cuenta las normas que han puesto en casa para poner límites a su uso. Cree que quitárselo no serviría pues donde vaya habrá un móvil que le permita seguir entrando a las redes. Intenta ponerse en su mente para comprenderla, pero no logra entender su adicción.

A continuación, Jordi Évole asiste a una terapia de jóvenes enganchados al móvil. A través de las preguntas que el terapeuta formula conocemos por boca de los jóvenes la relación que mantienen con esta tecnología, que se resume en un equivocado enfoque de la vida, problemas en el ámbito familiar y de amistad, bajo rendimiento escolar, cambio de hábitos en el sueño y pérdida de tiempo. Afirman que los adultos también hacen un mal uso, pero no tan descarado. Marc Masip, el terapeuta, añade desde su experiencia otras consecuencias negativas: la dependencia que degenera en agresividad, el chantaje emocional a los padres... Además, cuenta a Évole los indicios y síntomas que nos pueden indicar que tenemos dependencia del smartphone. Habla del perfil de sus pacientes y traslada la responsabilidad a los adultos, a su falta de criterio y autoridad en tantas ocasiones.

El programa introduce un golpe de efecto cuando el entrevistador pasa a ser entrevistado sobre su posible adición a la tecnología, y los cámaras que graban son enfocados y dialogan sobre este hecho.

Tras la voz del narrador -que recuerda que solo han pasado diez años desde que Steve Jobs presentó el primer iPhone, y que la llegada del smartphone significó una revolución que nos ha convertido en personas conectadas 24 horas al día- y el video de archivo de este momento, aparece la música y los créditos que presentan "Conectados". La voz de Steve Jobs acompañada de imágenes de todo tipo de personas usando un móvil en las circunstancias más inverosímiles, y la frase "es como tener tu vida en el bolsillo", dan paso al siguiente bloque.

Bloque-Adultos. Este apartado se compone de tres sugerentes sub-bloques. En el primero se suceden diversos testimonios de adultos que en videos caseros hablan de su relación con el móvil. Los ejes centrales de sus intervenciones recogen los siguientes tópicos: adicción, dependencia, sentirse esclavo y ser consciente de ello, falta de reflexión (no se procesa y se da una respuesta inmediata). Estas afirmaciones se refuerzan poderosamente con imágenes donde la presencia del móvil llega a las situaciones más inverosímiles o ridículas como puede ser una operación quirúrgica o el tiempo que se pasa en el WC.

A continuación, Évole en la mesa de una cafetería entrevista a Gustavo Entrala, emprendedor español que abrió la cuenta de twitter del Papa Benedicto XVI, y quien reconoce que él mismo acabó enganchado a las redes sociales. Entrala admite que entró en una espiral de narcisismo y exhibicionismo que hacía que estuviera más pendiente de su vida en las redes que de la vida real. Cuando se le pregunta si ha superado esta adición responde que no, y que siempre será preciso que luchemos con el estímulo inmediato de mirar el móvil. En este momento ambos se giran y Évole pregunta a un hombre que está sentado en una mesa cercana manipulando su móvil, sobre lo que está mirando. Comienza un diálogo donde este personaje cuenta su proceso de enganche y de lucha para evitar que este dispositivo afecte a su relación familiar. Termina el sub-bloque con imágenes de calles con gente que lleva su móvil en la mano y lo consulta. Entrala vuelve a intervenir catalogando este hecho como un fenómeno universal $\mathrm{y}$ termina afirmando que el no estar conectado es un problema y una actitud de lujo porque es algo inevitable; por lo que, añadirá, "tenemos que aprender a vivir así".

Una serie de preguntas dan paso a las entrevistas a pie de calle. ¿Somos conscientes de las horas que pasamos conectados al móvil cada día? ¿A qué edad se le puede dar un móvil a nuestros hijos? ¿Podríamos salir de casa sin el móvil? Las respuestas reflejan un deterioro de la comunicación en las relaciones de pareja y la dependencia de las multipantallas.

Bloque-Familias. Évole entrevista en la puerta de un colegio a seis padres de hijos de nueve años entre los que se encuentra un profesor. Dialogan sobre la edad para dar un móvil a sus hijos: hablan del momento en que dejan la educación primaria, cuando entran en el instituto (15-16 años), y el profesor, desde su experiencia puntualiza que esto ocurre a los 12 años. Todos coinciden en que cuanto más tarde, mejor. Y comparten que sufren enfrentamiento con los hijos a la hora de la cena para dejar el móvil. También reconocen haber entregado alguna vez el móvil a sus hijos de tres años para lograr que se callen. Concluyen que la presencia del móvil en la vida de los hijos es algo para asumir, que precisa ser racionales, fijar unas normas y, por supuesto, aprovechar lo positivo que tiene.

Bloque-Expertos. En este bloque analizaremos los textos y la entrevista inédita a Bauman. Cierto que a lo largo del programa aparecen otros actores que podrían ser calificados de expertos: es el caso de Marc Masip, psicólogo y terapeuta, o el de Gustavo Entrala, experto en redes sociales. Pero los contenidos de sus intervenciones aparecen vinculados, en el primer caso a los adolescentes, y en el segundo a los testimonios de los adultos que sufren dependencia del móvil entre los que se retrata el propio Entrala. Nos centraremos, pues, en el filósofo y sociólogo Zygmunt Bauman, presentado al final del programa en calidad de eminente teórico que reflexiona sobre la realidad social tratada. La presencia de Bauman adquiere un relieve especial. Su aportación es presentada a modo de reflexión teórica global, que busca desde la mayor abstracción y distancia encontrar coherencia y sentido al fenómeno de la comunicación en el mundo actual, en especial a través de redes sociales y con smartphones. Se añade como valor que dicha entrevista tuvo lugar poco antes de fallecer.

Alude Bauman a algunos estudios que indican que en los países tecnológicamente avanzados las personas pasan casi 10 hora de media frente a una pantalla, sea ordenador, tablet, televisión o smartphone. En esa "pantalla global" de la que hablaron Lipovetsky y Serroy (2009), ha ido aumentando la comunicación mediática unilateral (TV) o bidireccional (Internet a través de dispositivos emergentes). A las horas frente al TV, que en muchos casos suponen en la infancia una relación absorbente y de dependencia declarada, con promedios de visionado que se acercan a las 4 horas diarias en países occidentales (Sigman, 2005), hay que sumar ahora las horas frente a otro tipo de pantallas más interactivas, pero quizás por eso más adictivas, y que están abriendo nuevos cauces a la comunicación social, no siempre en positivo desde una perspectiva sociomoral.

Por ejemplo, se refiere Bauman a la soledad. "Ninguna de las conexiones tecnológicas es lo suficientemente profunda como para romper nuestra soledad". Hace ya casi una década que Dominique Wolton se refería justamente a la "soledad interactiva" que crece a la sombra de Internet. Idea que recoge Bauman, aunque sin nombrarlo, y que matiza con nuevas reflexiones desde una mirada más actual. Precisamente en la entrevista Bauman incide en la expresión "seres solitarios en permanente contacto" para referirse a la condición de tantas personas que en nuestras sociedades viven sumergidas en un entorno de comunicación precaria, superficial como afirmó Carr (2015), en la que más que diálogo prevalece el ruido, el intercambio exento de reflexión. La vorágine de mensajes e interacciones tecnocomunicadas no responde a lo que Kaplún (1998) defendiera como auténtica comunicación, ni a lo que Habermas (1995) proclamara como diálogo, dado que no se promueven ni garantizan las condiciones para el 
mismo en nuestros actos comunicativos (libertad, simetría, respeto al otro como interlocutor válido, veracidad, búsqueda de consenso a partir del mejor argumento, etc.).

Así, en nuestras "sociedades líquidas", tal como las denominó Bauman (2002) en una de sus obras más conocidas, nuestra relación con el tiempo es una relación conflictiva, signo de nuestro modo de ser posmoderno. Circunstancia que justifica la alusión de Bauman al regalo, a la recuperación de la idea de gratuidad, despojando al tiempo de su carga de productividad cuantificada: "el mejor regalo que puedes hacer a tu hijo es darle tu tiempo".

Volviendo a la idea de la soledad interactiva, Internet y las redes sociales están modificando nuestra experiencia de la relación humana y del diálogo interpersonal. ¿Qué somos capaces de hacer por miedo a la soledad? ¿Qué no haríamos por temor al rechazo, a la exclusión o la marginalidad comunicativa?

El creador de Facebook intuyó con una sagacidad fuera de toda duda que el miedo a sentirnos excluidos, rechazados o fuera de la órbita socio-comunicativa era un poderosísimo motor para entregarse al imán de una red de conexión social. "Nuestra peor pesadilla es ser abandonados", decía Bauman en alusión a la motivación humana que intuyó Zuckerberg cuando diseñó Facebook. En efecto, por miedo a la soledad y al abandono social, por huir de la anomia social, somos capaces de lo mejor... y de lo peor. En busca de reconocimiento forjamos un carácter virtuoso orientado a la excelencia (Aristóteles). Pero también por encajar en nuestro grupo o comunidad renunciamos a la búsqueda de propios patrones de vida, de autonomía moral (Kant), celebrando lo que convencionalmente se considera como bueno o justo (Kohlberg).

El nuevo entorno digital, en palabras de Bauman, se aprovecha de estas necesidades humanas para crear una ficción de diálogo, un espejismo de comunicación: las redes sociales no ayudan en sí mismas a profundizar en la experiencia dialógica, ni garantizan esas condiciones ideales de habla que habrían de presidir los actos comunicativos con el fin de resolver cuestiones de hecho (verdad) o cuestiones de intereses (bien o justicia), tal como destacó Habermas (1992). Al decir de Bauman en Salvados, "la gente joven no tiene habilidades sociales y sin el diálogo estamos perdidos", refleja en toda su crudeza las contradicciones y ambigüedades de nuestras sociedades líquidas, mediáticas y consumistas.

\subsection{Traslación del Modelo actancial de Greimas a la narración de "Conectados"}

El modelo actancial de Greimas se estructura con la simplificación de los roles que los personajes de un relato asumen en el desarrollo de la historia. Como modelo aplicable a cualquier texto narrativo, en "Conectados" reconocemos la estructura actancial de Greimas: los personajes asumen secuencialmente el rol de Sujeto que desea un Objeto. Este objeto de deseo se distribuye entre la permanente conexión (adolescentes y adultos singulares) y la consecución del equilibrio que en los expertos se traducirá en la preocupación por concienciar, alertar, y en su caso, reconducir.

El Ayudante varía en cada bloque: la presión social y el consumismo son comunes para los adolescentes y los adultos, a los que se suman en cada caso sus iguales: otros adolescentes y la presión del entorno profesional en el caso de los adultos. Las familias cuentan con la ayuda de los expertos en general y la escuela, y los expertos se sirven de los hallazgos científicos que refuerzan su deseo y la difusión de estos datos en los medios de comunicación.

El elenco de Oponentes recorre un sentido inverso: para los adolescentes el obstáculo serán sus padres, la escuela y los expertos que se oponen a sus deseos; en los adultos hay una fuerte oposición por su entorno más íntimo, normalmente su pareja, y por la propia autoconciencia de pérdida de valores y de espacios de libertad. Las familias y los expertos coinciden y se sienten obstaculizados por la presión social, la pérdida de autoridad frente a los hijos y las carencias de formación en educomunicación.

El Destinador como fuerza -el qué o quién- que motiva al sujeto a cumplir su objetivo, en los adolescentes se identificaría como el poder y la satisfacción que les da el navegar por las redes favoritas, contactar con sus amistades, el prestigio de tener muchos seguidores y el hecho de sentirse parte del grupo. Los adultos lo traducen en la satisfacción de controlar sus propias vidas ("es como llevar tu vida en el bolsillo"), y el poder que da la información. Por su parte las familias lo concretan en poder, pero en este caso sobre los hijos y el equilibrio entre la vida virtual y la real. Los expertos persiguen la excelencia y los valores que transforman la sociedad cívica en sede de la libertad y el respeto.

El Destinatario -quién o qué recibe las metas o acciones del sujeto- se presenta de la siguiente manera: en los adolescentes, otros adolescentes y las empresas de telecomunicación que reciben los beneficios de esta permanente conexión; en los adultos, sus interlocutores, sean otros adultos o la empresa profesional beneficiaria en gran medida del uso de esta permanente conexión, e igualmente, las empresas de telecomunicaciones. En el caso de las familias su deseo se traduce en una convivencia más feliz y armónica; finalmente los expertos tienen como destinatario la sociedad civil que en este caso adquiriría las características de libre y democrática.

Tabla 2. Análisis de la estructura actancial de "Conectados"

\begin{tabular}{|c|c|c|c|c|c|}
\hline sujeto & objeto & ayudante & oponente & destinador & destinatario \\
\hline adolescentes & $\begin{array}{l}\text { conexión las } 24 \\
\text { horas }\end{array}$ & $\begin{array}{l}\text { presión social } \\
\text { consumismo } \\
\text { otros adolescentes }\end{array}$ & $\begin{array}{l}\text { padres } \\
\text { escuela } \\
\text { expertos }\end{array}$ & $\begin{array}{l}\text { poder } \\
\text { satisfacción } \\
\text { prestigio (seguidores) } \\
\text { sentido de } \\
\text { pertenencia }\end{array}$ & $\begin{array}{l}\text { adolescentes } \\
\text { empresas de } \\
\text { Telecomunicación }\end{array}$ \\
\hline adultos & $\begin{array}{l}\text { conexión las } 24 \\
\text { horas }\end{array}$ & $\begin{array}{l}\text { presión social } \\
\text { consumismo } \\
\text { presión profesional }\end{array}$ & $\begin{array}{l}\text { autoconciencia } \\
\text { pareja } \\
\text { valores }\end{array}$ & $\begin{array}{l}\text { poder } \\
\text { satisfacción } \\
\text { control de la propia } \\
\text { vida }\end{array}$ & $\begin{array}{l}\text { adultos } \\
\text { empresas de } \\
\text { Telecomunicación } \\
\text { ámbito profesional }\end{array}$ \\
\hline
\end{tabular}




$\begin{array}{lllll}\text { sujeto } & \text { objeto } & \text { ayudante } & \text { oponente } & \text { destinador } \\ \text { familias } & \begin{array}{l}\text { éxito familiar } \\ \text { control }\end{array} & \begin{array}{l}\text { expertos } \\ \text { escuela }\end{array} & \begin{array}{l}\text { presión social } \\ \text { falta de autoridad } \\ \text { falta de formación }\end{array} & \begin{array}{l}\text { poder } \\ \text { equilibrio }\end{array} \\ \text { expertos } & \begin{array}{l}\text { concienciar } \\ \text { alertar } \\ \text { curar }\end{array} & \begin{array}{l}\text { estadísticas } \\ \text { investigaciones } \\ \text { medios de } \\ \text { comunicación }\end{array} & \begin{array}{l}\text { presión social } \\ \text { falta de autoridad } \\ \text { parental } \\ \text { falta de formación }\end{array} & \begin{array}{l}\text { excelencia } \\ \text { valores respeto, } \\ \text { consenso, libertad }\end{array}\end{array}$

\section{Conclusiones}

El estudio del programa "Conectados" de Salvados, desde una visión semiótica comunicacional, nos conduce a las siguientes conclusiones:

En primer lugar, comprobamos que este tipo de análisis efectivamente favorece la profundización en los códigos de comunicación, el contexto cultural y su composición simbólica, hechos que como afirmábamos en el apartado de la metodología, repercuten en conductas de consumo del medio. Recordemos que uno de los objetivos propuestos en este estudio perseguía determinar si la posibilidad de estar continuamente conectados al smartphone nos empodera o nos empobrece, y en qué sentido lo hace. Con ese fin y tal y como nos proponíamos en el segundo objetivo hemos recogido y contrapuesto los aspectos positivos y negativos del uso de esta tecnología. Así, tras el análisis de contenido podemos afirmar que, si bien hay una conciencia general en la ciudadanía de las consecuencias positivas y beneficiosas que esta tecnología conlleva, la idea del empobrecimiento prevalece. Tanto los jóvenes como los adultos reconocen la tiranía que el móvil ejerce en sus vidas. Padres, madres y educadores son conscientes de la necesidad de planes de acción y prospectivas que contrarresten los efectos negativos ya arraigados por el mal uso que genera la tecnología.

Pero no solo basta el diagnóstico inmediato. También nos proponíamos dibujar un marco de referencia que pudiera servir en el diseño de propuestas pedagógicas destinadas a la educación mediática de la ciudadanía (educomunicación). En este sentido el sociólogo Bauman analiza y toma el pulso a nuestras sociedades, mostrando una situación en la que con finura constata la condición de nuestro tiempo: los significados que nos envuelven y que definen nuestra identidad comunicativa están sometidos a constante cambio, a un flujo y dinamicidad permanentes. Nuestros actos comunicativos se construyen desde conceptos líquidos, evanescentes y fragmentados semánticamente, pues han sucumbido en la posmodernidad las significaciones estables, rígidas, sólidas (Green y Gary, 2016).

Pero por otra parte, el Bauman filósofo y pedagogo crítico no se resigna al desconcierto y las carencias relacionales de nuestro tiempo, carencias a cargo de la irrupción comunicativa del smartphone. Como bien notara Sarid (2017), el Bauman sociólogo no se queda en el nivel de lo fáctico. Cuando se enfrenta al problema de la educación, Bauman (2005) se sitúa en un metanivel contrafáctico, dado que educar implica por necesidad el recurso a un proyecto ideal y transformador, factible pero asimismo válido éticamente. La comunicación líquida que crece a la sombra del smartphone (entiéndase líquida por superficial, que fluye sin mesura, hueca e inconexa, efímera y transitoria) ha de buscar complemento en una perspectiva ética más "sólida" por seguir con la metáfora, con elementos para la crítica más intersubjetivos y consensuados. Bauman en la entrevista no sólo retrata, sino que denuncia. Presupone un referente crítico que le conduce a catalogar nuestra actual situación de habla como carencial y precaria.

En los contenidos de "Conectados", se pone de manifiesto la necesidad de ampliar la pedagogía líquida, alumbrada en otros momentos por Bauman. El Bauman sociólogo, aunque no establece una reflexión sistemática sobre la educación, sí que se atreve con la definición de los fines propios de ésta: educar, tal como ocurre desde la antigüedad clásica, es una tarea cuyo fin es preparar a los niños y jóvenes para la vida (Bauman, 2011). Sin embargo, esta preparación para la vida, en la línea del pragmatismo, parece soslayar aspectos morales y críticos en el proceso educativo como proceso también de transformación social, no sólo de adaptación o reproducción.

Pero, como indicábamos, en el programa “Conectados" Bauman alude implícitamente a la necesidad de asumir social y educativamente una actitud proactiva, de transformación, que se puede condensar en la idea de educar para la apropiación crítica de los medios y de la realidad provocada por los nuevos dispositivos de comunicación. Educación mediática que pasa por tomar consciencia del "diablo que llevamos dentro", y por intensificar formas de comunicación (diálogo) enriquecedoras, necesarias para romper con la soledad interconectada a la que nos somete el nuevo entorno tecnológico.

\section{Referencias bibliográficas}

Bauman, Z. (2002). Modernidad líquida. México: Fondo de Cultura Económica

Bauman, Z. (2005). Education in liquid modernity. Review of Education, Pedagogy, and Cultural Studies, 27, 303-317. https://doi. org/10.1080/10714410500338873

Bauman, Z. (2011). Liquid modern challenges to education. In S. Robinson \& C. Katulushi (Eds.), Values in Higher Education (pp.36-50). St Brides Major, UK: Aureus / University of Leeds.

Cappelletti, M. \& Domínguez, A. (2014). La curaduría de contenidos y la narrativa colaborativa en el Ciberperiodismo: estudio del caso de Storify en el diario digital elpais. com/Content Curation and collaborative narrative on Webjournalism: a study case of Storify in the digital newspaper elpais. com. Estudios sobre el Mensaje Periodístico, 20(1), 17-33.

Carr, N. (2015). Superficiales. ¿Qué está haciendo Internet con nuestras mentes? Madrid: Taurus.

Galán-Linares, E. (2014). Salvados: ¿comunicación alternativa o la excepción que confirma la regla? Trabajo Fin de Grado en Periodismo de la Universidad de Sevilla. https://goo.gl/Yu7hp2

García-Contto, J. (2011). Manual de semiótica: semiótica narrativa, con aplicaciones de análisis en comunicaciones. https:// goo.gl/41YqPx

Gao, Y., Li, A., Zhu, T., Liu, X., \& Liu, X. (2016). How smartphone usage correlates with social anxiety and loneliness. PeerJ, 4, e2197. https://goo.gl/NyLqAn. https://doi.org/10.7717/ peerj.2197 
González, C. y Fanjul, C. (2018). Aplicaciones móviles para personas mayores un estudio sobre su estrategia actual, Aula Abierta, 47(1), 107-112. https://doi.org/10.17811/rifie.47.1.2018.107-112

Gracia, J. \& Gozálvez, V. (2016). Justificación filosófica de la educación en valores éticos y cívicos en la educación formal. Análisis crítico de la LOMCE. Teoría de la Educación. Revista Interuniversitaria, 28 (1), 83-103.

Green, L. \& Gary, K. (2016). Pedagogy for a Liquid Time. Studies in Philosophy and Education, 35, 47-62.

Habermas, J. (1995). Conciencia moral y acción comunicativa. Barcelona: Península.

Habermas, J. (1992). Postmetaphysical thinking. Cambridge, MA: MIT Press.

Hartanto, A., \& Yang, H. (2016). Is the smartphone a smart choice? The effect of smartphone separation on executive functions. Computers in Human Behavior, 64, 329-336. https://goo. gl/QdjUJi

Horizon Report (2016). Higher Education Edition. http://cdn. nmc.org/media/2016-nmc-horizon-report-he-EN.pdf

Ditrendia (2017). Informe Mobile en España y en el Mundo 2017. https://goo.gl/u4zpfb

Johnson, L., Adams Becker, S., Estrada, V., \& Freeman, A. (2014). NMC Horizon Report: 2014 K-12 Edition. Austin, Texas: The New Media Consortium. https://goo.gl/45JHYp

Kaplún, M. (1998). Una pedagogía de la comunicación. Madrid: Ediciones de La Torre.

Lipovetsky, G. \& Serroy, J. (2009). La pantalla global. Cultura mediática y cine en la era hipermoderna. Barcelona: Anagrama.

Luengo-De la Torre, M. (2012). Una aproximación al concepto de Sociedad Móvil: el smartphone: su expansión, funciones, usos, límites y riesgos. Derecom, (11), 10.

Malaina-Abad, B. (2015). Análisis comparativo de la audiencia social de La Sexta Noche y Salvados: la política en prime time y la formación de la esfera pública digital. Trabajo Fin de Master Universidad Complutense de Madrid, https://goo. $\mathrm{gl} / 2$ tpazT

Mancinas-Chávez, R., \& Galán-Linares, E. (2014). El programa 'Salvados' en el sistema audiovisual español: elemento herético o la excepción que confirma la regla. Anduli: Revista Andaluza de Ciencias Sociales, 13, 119-136.
Merino-Arribas, A. (2013). El factor emocional en la narrativa transmedia y la televisión social. Fonseca, Journal of Communication, (6), 234-257.

Pearson, C. \& Hussain, Z. (2016). Smartphone addiction and associated psychological factors. Addicta: The Turkish Journal of Addictions. Online First. https://doi.10.15805/addicta.2016.3.0103

Ramos-Soler, I., López-Sánchez, C. \& Torrecillas-Lacave, T. (2018). Online risk perception in young people and its effects on digital behaviour. [Percepción de riesgo online en jóvenes y su efecto en el comportamiento digital]. Comunicar, 56, 71-79. https://doi.org/10.3916/C56-2018-07

Reid D.J. \& Reid F.J. (2007). Text or talk? Social anxiety, loneliness, and divergent preferences for cell phone use. CyberPsychology \& Behavior. 2007; 10(3): 424-435. https://doi.10.1089/ cpb.2006.9936

Rodríguez-Gómez, D., Castro, D. \& Meneses, J. (2018). Problematic uses of ICTs among young people in their personal and school life. [Usos problemáticos de las TIC entre jóvenes en su vida personal y escolar]. Comunicar, 56, 91-100. https://doi. org/10.3916/C56-2018-09

Rodrigo, M.J., Martínez, R., \& Rodríguez-Ruiz, B. (2018). La Relación Centro Escolar-Familia como Factor Protector de Conductas Transgresoras en la Adolescencia. Aula Abierta, 47(2), 149-158. https://doi.org/10.17811/rifie.47.2.2018.149-158

Sarid, A. (2017). Self-critical appropriation: An assessment of Bauman's view of education in liquid modernity. Educational philosophy and theory, 49 (5), 462-472.

Sigman, A. (2005). Remotely controlled. How television is damaging our lives. London: Vermilion.

Thomée, S., Härenstam, A., \& Hagberg, M. (2011.) Mobile phone use and stress, sleep disturbances, and symptoms of depression among young adults - a prospective cohort study. BMC Public Health 11(1):66. https://doi.10.1186/1471-2458-11-66.

Tubau, D. (2015). El espectador es el protagonista. Madrid: Alba.

Zambrano, V.M., \& Castells, A.G. (2016). Aproximación al potencial colaborativo de la narrativa documental interactiva en los procesos de cambio social. Cultura, Lenguaje y Representación/Culture, Language and Representation, 15, 153-169. 